\title{
COMPARISON OF MATHEMATICAL MODELS FOR HEAT EXCHANGERS OF UNCONVENTIONAL CHP UNITS
}

\author{
Peter ĎurČAnskÝ ${ }^{a, *}$, Richard Lenhard ${ }^{b}$, Jozef JAndaČKa $^{b}$ \\ ${ }^{a}$ University of Žilina, Research Centre, Univerzitná 8215/1, Slovak Republic \\ ${ }^{b}$ University of Žilina, Faculty of Mechanical Engineering, Department of Power Engineering, Univerzitná \\ 8215/1, Slovak Republic \\ * corresponding author: peter.durcansky@rc.uniza.sk
}

\begin{abstract}
An unconventional CHP unit with a hot air engine is designed as the primary energy source with fuel in the form of biomass. The heat source is a furnace designed for combustion of biomass, whether in the form of wood logs or pellets. The transport of energy generated by the biomass combustion to the working medium of a hot-air engine is ensured by a special heat exchanger connected to this resource. The correct operation of the hot-air engine is largely dependent on an appropriate design of the exchanger. The paper deals with the calculation of the heat exchanger for the applications mentioned, using criterion equations, and based on CFD simulations.
\end{abstract}

KEYWORDS: heat exchanger; CFD simulation; hot air engine.

\section{UnCONVENTIONAL CHP UNIT}

The burning of fossil fuels in internal combustion engines, in gas turbines, in steam power plants and in other facilities represent various possibilities of electricity production. Except for units with internal combustion engines, these are large devices which require intensive operation and maintenance. Another problem is the dependence of such devices on fossil fuels. Hot air engines, namely the Stirling and Ericsson engines, offer a possible alternative to conventional internal combustion engines. The scheme of these machines is shown in Fig. 1 .

In the case of the Stirling engine, the double function of the regenerator is immediately obvious. The regenerator $(\mathrm{R})$ functions as a heater or cooler and enables energy storage, while in the Ericsson engine the cooler and heater are separate heat exchangers and he efficiency of the machine is not as significantly affected by the volume of the regenerator as in the case of the Stirling engine. 1] In the Ericsson cycle, air is compressed in the compression cylinder, then it flows through the heat exchanger, where the air receives heat energy at a fixed pressure. Subsequently, it is led into the expansion cylinder, which expands adiabatically and performs work. 2] Part of the work

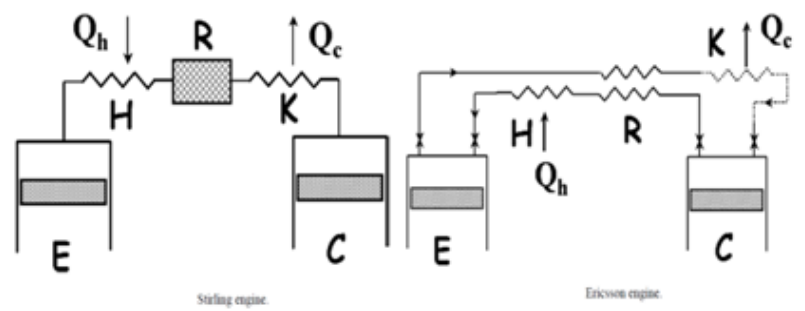

Figure 1. Stirling and Ericsson engine [1]. is used to drive the compressor and the rest can be used as mechanical work to drive an electric generator.

The source of heat for the proposed system with a hot air engine is a furnace designed to burn biomass, whether in the form of wood logs or pellets. The transport of energy generated by the combustion of biomass to the working medium of the engine is provided by a heat exchanger connected to that source.

We have also made another proposal which uses the Stirling engine with a different setup. The commercially available Stirling engines use natural gas as their heat source. Natural gas is burned in a burner and is led to the internal heat exchanger, which is part of the regenerator. The emissions from natural gas burning contain neither particles nor dust that can pollute the internal exchanger. A different situation occurs during biomass burning. The flue gases contain many particles, dust, and ash, and a direct use of flue gases to heat up the internal heat exchanger is not the best solution, as the exchanger gets fouled. Thus

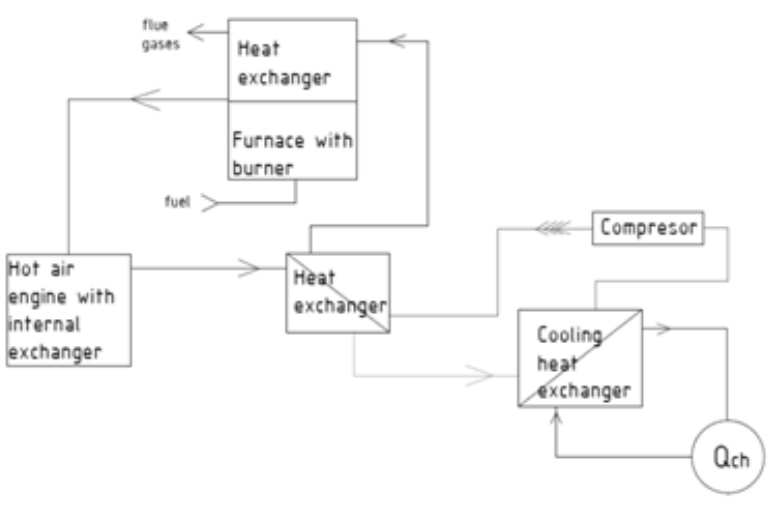

Figure 2. Proposed setup of experimental hot air engine. 


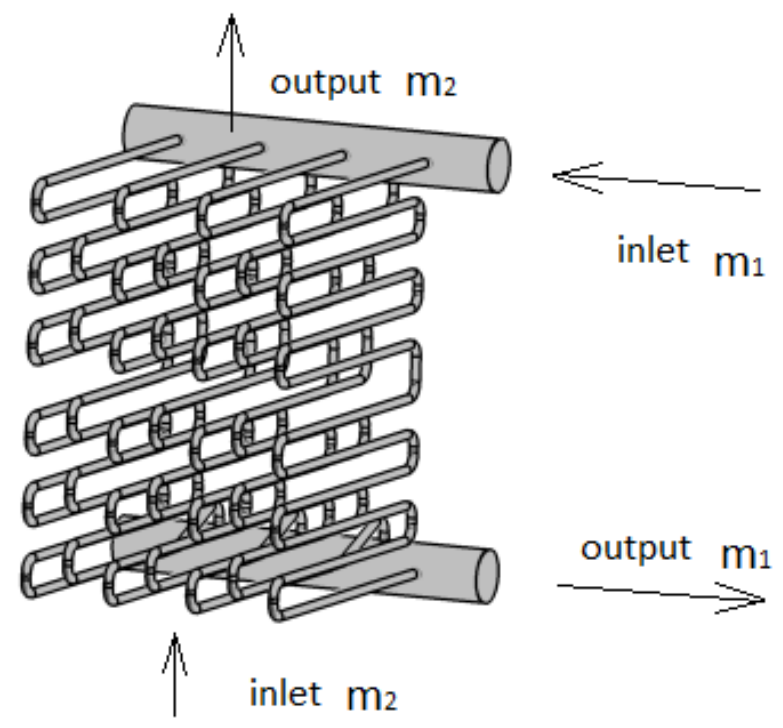

FIGURE 3. Schematic drawing of the proposed heat exchanger.

we decided to use another heat exchanger, placed directly in the biomass furnace, as an intermediate component, as shown in Fig. 2 This enables us to refund the energy supplied to the internal exchanger of the engine. The energy from the combustion of natural gas was replaced with the energy of the working medium, obtained and heated from biomass combustion. With such an involvement it was also necessary to ensure the delivery of the working fluid from the heat exchanger to the regenerator chamber of the Stirling engine. Delivering the medium by a blower or compressor was chosen as the best solution.

The compressor is connected to a closed circuit, which allows the use of a working medium at higher pressure. However, there is another problem: the need to keep the temperature of the working medium at the inlet to the compressor at the value specified by the manufacturer. Therefore, two heat exchangers were included. The second heat exchanger is used to recover heat energy to the medium, which flows from the compressor. This heat exchanger serves as a regenerator, retrospectively obtaining heat. Next, a cooling exchanger is used for cooling the working medium prior to its entering the compressor at the desired temperature. This exchanger also supplies hot water for heating.

\section{Design of the heAt EXCHANGER}

When designing a new exchanger, it is necessary to take into account all the conditions imposed on the exchanger and its desired properties. The most frequently investigated feature of heat exchangers is the heat exchange surface, from which all the other parameters of the exchanger are derived. We decided to use a countercurrent heat exchanger of gas-gas type for our application of the heat exchanger to a hot air engine. The gas, which receives the heat, is either dry air or any of the inert gases, such as nitrogen. The main requirements for this exchanger are therefore be slightly different. One of the important conditions is its strength, needed even at high combustion gases temperatures. [3] The use of tubes with a meandering shape, adapted to the shape of the built-in volume, proved to be the best arrangement. The tubes have a common collector at the inlet and at the outlet. 4 The proposed design of the exchanger is shown schematically in Fig. 3 The air enters the upper collector tube and heated air emerges from the lower header. In the space between the tubes, air flows vertically. The exchanger is designed as a cross-countercurrent, which will bring savings in terms of built-in volume. This arrangement also makes it possible to work with smaller temperature gradients. After a preliminary determination of the dimensions, we proceeded to calculate the heat exchanger using numerical methods.

\section{Calculation of the heat EXCHANGER USING NUMERICAL METHODS}

The aim of designing the heat exchanger using criteria equations is to determine the geometry of the heat exchanger. Heat transfer surface verification is also needed for specified temperatures and desired flow rate. Another aim of the analysis of the proposed exchanger, which is carried out using numerical methods, can be the verification of both the design correctness and of the boundary conditions, including temperature, flow rates or pressure losses. Because the heat transfer in the heat exchanger is a three dimensional timeindependent process, it is described by a system of partial differential equations, which had to be solved with numerical methods.

Our first step was to set up the working conditions of the combined heat power plant. Our application with the hot air engine sets a wide range of specifications not only on the heat exchanger, but also on the whole system. We are assuming the temperature of the working fluid, after expansion, ranges from $240^{\circ} \mathrm{C}$ to $320^{\circ} \mathrm{C}$ [4]. We set characteristic temperatures and physical properties for each working fluid, for the dry air in the tubes and for the exhaust gases outside the tubes. For the formula we use literature [6, 7].

The main temperature for heat transfer through the pipes in the bundle is:

$$
\Delta T_{\ln }=\frac{\Delta T_{\max }-\Delta T_{\min }}{\ln \frac{\Delta T_{\max }}{\Delta T_{\min }}}
$$

If the tubes are straight or staggered, the difference is characterized by dimensionless constants. If the tube bundle has a horizontal spacing $s_{1}$ and a vertical spacing $s_{2}$, we can characterize the bundle with these constants:

$$
a=\frac{s_{1}}{d_{0}}
$$




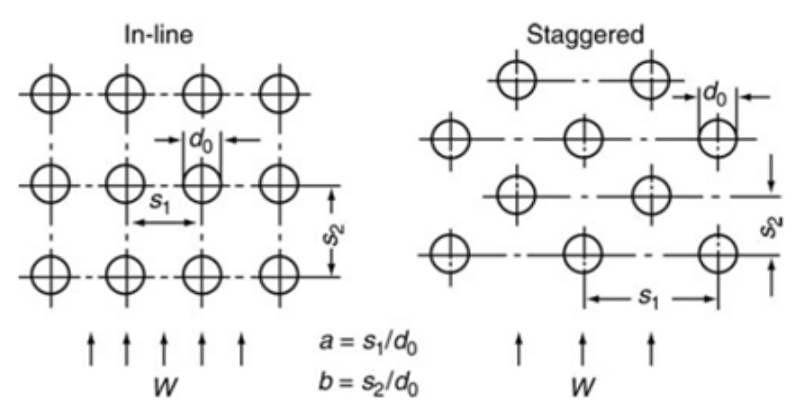

FIgURE 4. Lateral and longitudinal spacing in the tube bundles.

$$
\begin{gathered}
b=\frac{s_{2}}{d_{0}}, \\
\psi=1-\frac{\pi}{4 a} .
\end{gathered}
$$

We can also define the streamed length $l$, which can be expressed as the length of the flow path transverse over a single tube [7]:

$$
l=\frac{\pi}{2} d_{0}
$$

Another difference can be seen in the non-dimensional criteria. The Reynolds number characterizes the flowing medium and the type of flow. It is dependent on the flow velocity and also on geometry. For heat transfer through tubes in the bundle, the following Reynolds number criteria can be used:

$$
\operatorname{Re}=\frac{w l}{\psi \nu} .
$$

The Nusselt number $\nu$ characterizes the heat transfer. If the turbulence in the inflowing medium is low, deviations in the Nusselt number may occur. The average Nusselt number in a cross-flow over a bundle of smooth tubes can be calculated from the Nusselt number in a cross-flow over a single tube. For our purpose we used the criteria equation according to [7, 8]. The heat transfer is described by the 2 parts of the flow - the turbulent part and the laminar part of the flow near the walls:

$$
\begin{gathered}
\nu_{\text {l,lam }}=0.664 \sqrt{\operatorname{Re}_{\psi l}} \sqrt[3]{\operatorname{Pr}}, \\
\nu_{\text {l,turb }}=\frac{0.038 \operatorname{Re}_{\psi l}^{0.8} \operatorname{Pr}}{1+2.443 \operatorname{Re}_{\psi l}^{-0.1}\left(\operatorname{Pr}^{2 / 3}-1\right)} .
\end{gathered}
$$

If $\operatorname{Re}>10^{4}$, there is turbulent flow in the pipe. In the transition region of the Reynolds number from 2300 to $10^{4}$, the type of flow is also influenced by the nature of the inlet stream and by the form of the pipe inlet. Tube bundles with in-line tubes behave more like parallel channels which are formed by the tube rows. No expected increase in the heat transfer coefficient, due to the turbulence enhancement, caused by the tube rows, occurs. [7]

Our application for the hot air engine will use the heat exchanger with staggered tubes as the primary heat exchanger. For this type of heat transfer through a tube bundle, we can define, according to [7, the average Nusselt number for the bundle:

$$
\nu_{0, \text { bundle }}=\frac{1+(n-1) f_{\mathrm{a}}}{n} \nu_{1,0},
$$

where

$$
\begin{gathered}
f_{\mathrm{a}, \text { stag }}=1+\frac{2}{3 b}, \\
\nu_{1,0}=0.3+\sqrt{\nu_{1, \text { lam }}^{2}+\nu_{1, \text { turb }}^{2}} .
\end{gathered}
$$

An estimation of the overall coefficient of heat transfer, depending on the Nusselt number, then follows.

$$
\alpha=\frac{\nu_{\text {bundle }} \lambda_{\mathrm{TM}}}{l} .
$$

The overall coefficient of heat transfer has been set for both mediums; the coefficient of thermal conductivity for the wall is known. When we know both sides of the equation, we can compare them and estimate the overall heat transfer coefficient, as well as the needed heat transfer surface.

The calculation of the heat exchanger based on the above-mentioned relationships was implemented in a spreadsheet processor; after taking into account the possibilities of structural arrangements, the heat exchanger was designed and was verified by using a numerical finite element method.

\section{Design AND preparation of the NUMERICAL MODEL}

The Ansys Fluent computing environment was used for the solution of the heat transfer simulation. The first step was to replace the exchanger constructed in a 3D design program with a simplified model, shown in Fig. 5. To speed up the calculation and facilitate the generation of a computing mesh, the model was simplified and the parts which have a negligible effect on the result were not taken into account. Only the basic tube bundle and the outer volume which is connected to the heat exchange surface were left.

The model consists of two volumes, where one volume is a tube bundle and the second is the outer volume that encloses the entire exchanger and represents the gas volume. The next step was to create a computational mesh representing the distribution system of the computational domain into sub interlinked volume elements or cells. The number of cells and the quality of the network are the main factors influencing the accuracy of the mathematical model and of the calculation. In practice, the amount of cells in the calculated area is in an order of millions to tens of millions. The calculation becomes even more difficult if the grid has more cell volumes. Due to the complicated geometry of this model, it is difficult to establish a computing mesh. The only possibility of creating a mesh was the creation of very small elements. The aim was to create a simple mesh using automatic methods. 

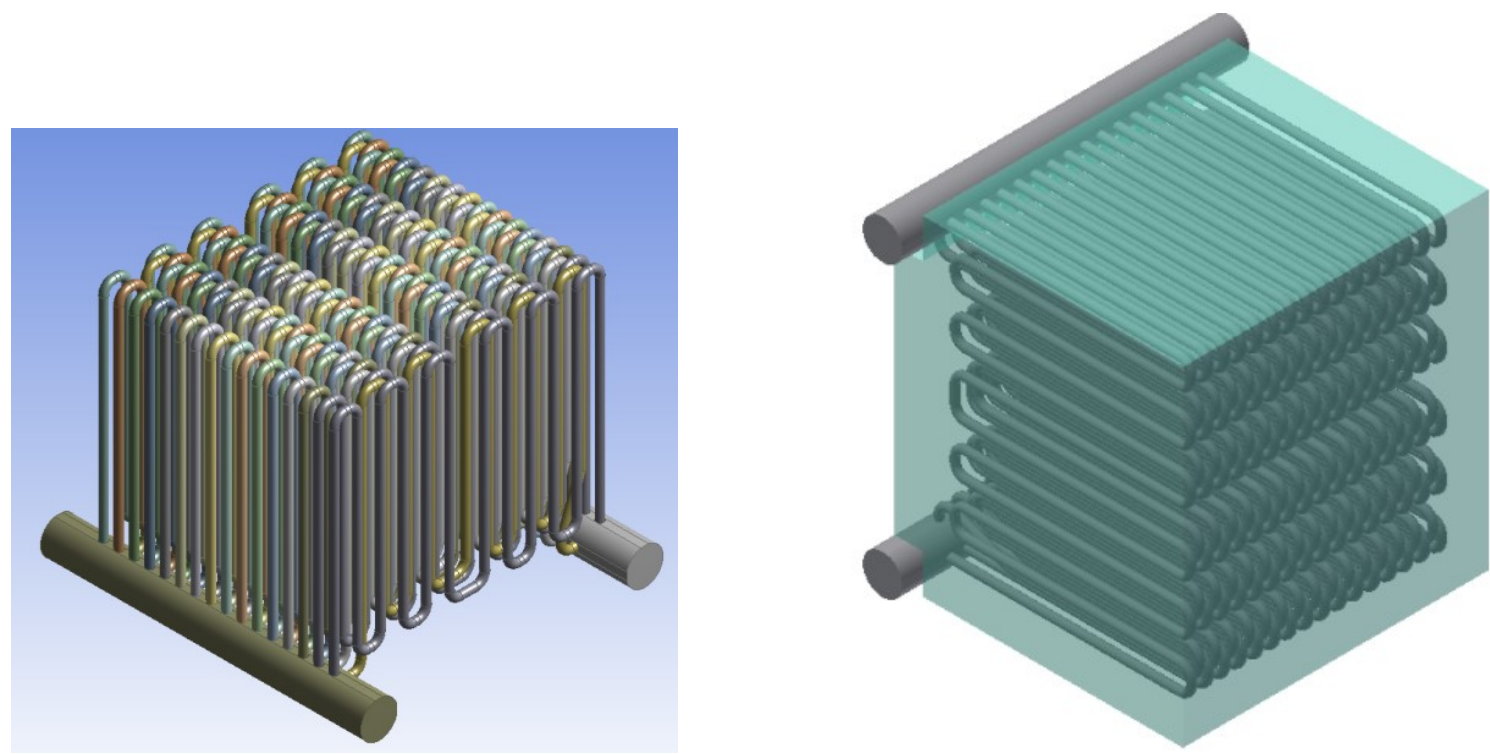

Figure 5. Simplified model of heat exchanger.
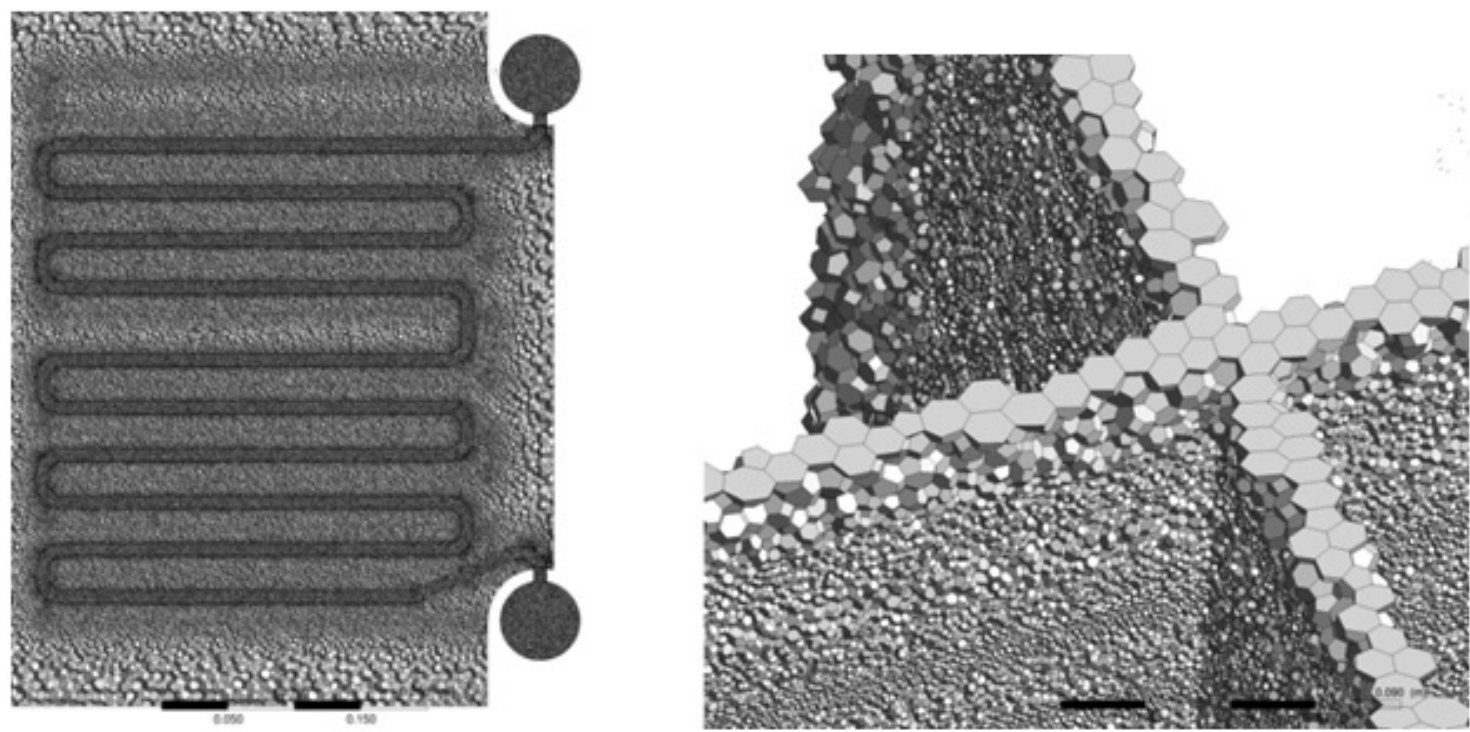

Figure 6. Polyhedral mesh.

The complex geometry has caused mesh creation problems, because the size of the elements has to be small enough to ensure that the elements can be formed in such a small area; therefore it was necessary to create a large number of elements. A triangular mesh was created, and in the basic mesh sizing settings an element with a minimal size of $0.5 \mathrm{~mm}$ was defined. The other settings remained default.

The required parameters for the calculation were proposed in three data models. Different possibilities for creating a computational mesh were used. The formation of the mesh was also treated in different ways, which is reflected in the quality of the mesh and in the results. A tetrahedron mesh and a polyhedra mesh were generated using the automated method, and subsequently acceded to another technique. To raise the quality, square or cubical elements can also be used; they speed up the calculation because they are the simplest of all types. Because the geometry of the model is too complicated, it was only possible to create a quadratic network in the exchanger tubes. The rest of the model was meshed with tetrahedron elements. The hexagonal network was created using the sweep method. This step also required the division of the heat exchanger into separate tube volumes. The other settings of this method remained default. The air - air type was chosen for the model and efforts were made to simplify the model adequately. The specific heat capacity of air was linearly dependent on the temperature. Steel was chosen for the walls of the tubes. It was also necessary to assign a type of material - solid or fluid- to each volume. In this case there were two volumes of selected types of fluid and in the editing options air was selected for both volumes. The model was designed as a time independent calculation and it takes into account the gravitational 

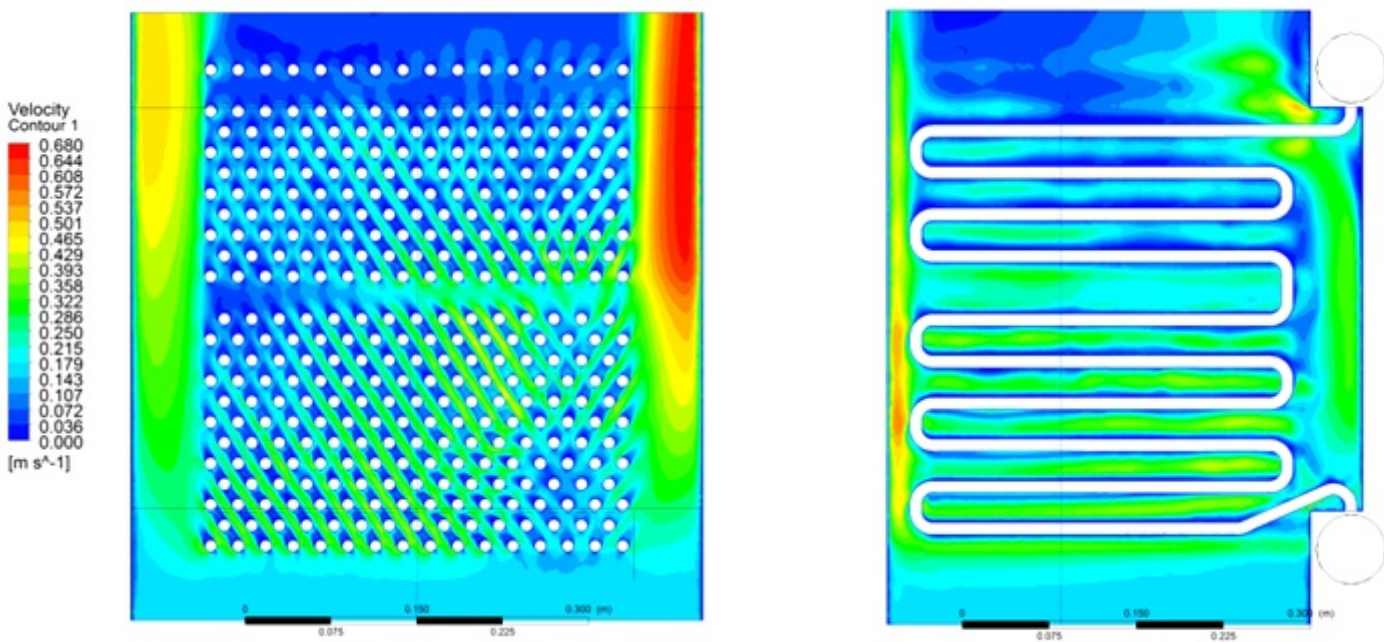

Figure 7 . The velocity profile in section planes.

force. Boundary conditions were set as input data. Flue gas and dry air were set as types of transport medium. The mass flow rate, turbulence intensity and hydraulic diameter were specified at the pressure inlet. The input pressure of the air and of the flue gases was also selected.

\section{Evaluation of THE NUMERICAL SIMULATION}

The result of the CFD simulation is a mathematical model that describes state values and changes in the heat exchanger. A calculation software allows viewing these values in any part of the heat exchanger, as well as in section planes.

The first observed variable was the performance of a heat exchanger of $12.8 \mathrm{~kW}$. When compared with a mathematical model that uses criteria equations, the deviation was only $6 \%$. Based on the CFD simulation, the profile of flow velocity in the section plane was then shown - see Fig. 7. There we can see the speed profile of the flow in the exchanger in the section planes. At first glance, the visible area on the side of the heat exchanger has higher flow velocities. These velocity fields are undesirable, because there is no reason for a sudden change in velocity in these areas. It is therefore a mistake, or rather a deviation in the calculation model in these areas. In other areas we can observe a flow of flue gases, which has a partly turbulent character. After a few rows of tubes, we can also observe a normalization of the flow in the space between the tubes. The flow is regulated and extends to the entire area of the heat exchanger, which is very appropriate. Despite this, it will be necessary to use additional design elements and adjustments to influence the flow before it joins the exchanger.

In Fig. 8, we can see the temperature contours in section planes in the exchanger. The aim was to verify the predicted temperatures at the inlet and at the outlet. The only specified boundary conditions were the input temperature of flue gas from the furnace and

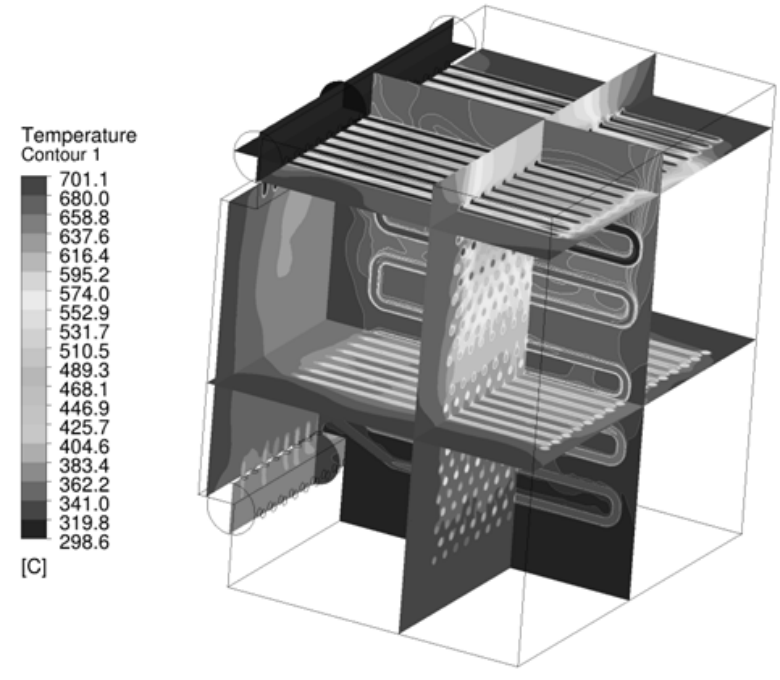

Figure 8. Temperature overview in 3D cross section.

the inlet air temperature. The other temperatures were computed by a mathematical model. The calculation showed that the real temperature of the heated air may be higher than predicted, in this case about $600^{\circ} \mathrm{C}$, which is about $100^{\circ} \mathrm{C}$ above the prediction. This testifies to an oversizing of the heat exchanger, which was taken into account when compiling the mathematical model.

However, in practice, a different situation may arise. Especially after long periods of operation, the heat exchanger can get clogged and the thermal resistance can increase. A reduction in the overall coefficient of heat transfer can thus subsequently lead to a decline in the performance of the heat exchanger. Figure 9 shows a view of the thermal field. Again, we can see the sides of the thermal field whose temperature is higher than the temperature between the tubes. As mentioned above, the flow of the sides can be influenced by free volume, where a greater amount of exhaust gases can flow, due to lower pressure resistance. 


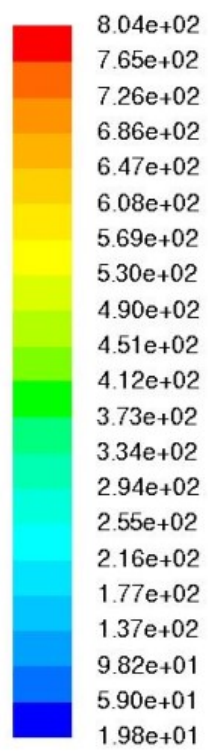

Figure 9. Temperature overview in cross section.

When constructing the heat exchanger, these findings will be taken into account, and the exchanger wall will be situated within close proximity to the heat exchanger tubes.

\section{Conclusions}

The heat exchanger is a technical device whose function is to transfer heat from one environment to another, from one fluid to another. The energy transfer should involve, as far as possible, as little loss as possible. The exchanger has to meet specific requirements in terms of lifetime. It must be able to withstand aggressive environmental influences, such as corrosion, and it must also be possible to at least partially restore its properties by cleaning or replacing exposed parts.

The aim of our models was to verify the predicted temperatures at the inlet and the outlet. The calculation showed that the predicted temperature of the heated air may be higher than anticipated. This testifies to the oversizing of the heat exchanger, which was taken into account when compiling a mathematical model.

\section{ACKNOWLEDGEMENTS}

This work is supported by "Výskum nových spôsobov premeny tepla z OZE na elektrickú energiu využitím nových progresívnych cyklov," ITMS 26220220117 (50\%). This work is supported by the European Regional Development

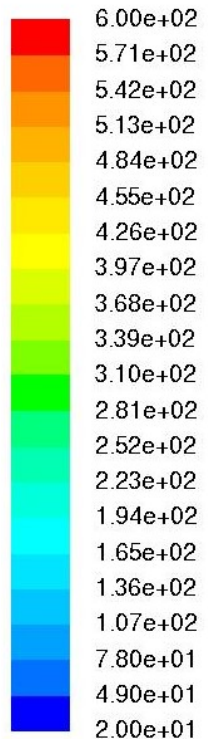

Figure 10. Temperature overview in cross section.

Fund and the State budget as part of the "Research Center of University of Zilina" ITMS 26220220183 project (50\%).

\section{REFERENCES}

[1] Creyx M., Energetic optimization of the performances of a hot air engine for micro-CHP systems working with a Joule or an Ericsson cycle, Elsevier, France, 2012.

[2] Kalčík J., Sýkora K.: Technická termodynamika, Praha: Academia Praha, 1973, pp. 301 - 318.

[3] Bonnet S., Alaphilippe M., Stouffs P, Energy, exergy and cost analysis of a micro-cogeneration system based on an Ericsson engine, Elsevier, France, (2011)

[4] Ďurčanský P., Jandačka J., Kapjor A., Papučík Š, Návrh výmenníka tepla pre Ericsson-Braytonov motor, in SKMTaT 2013 (ed. K. Kaduchova), Tatranská Lomnica, Slovakia, 2013, pp. 21-25

[5] Verein Deutscher Ingenieure, VDI heatatlas, Berlin Heidelberg: Springer-Verlag, 2010, pp. 720-740.

[6] R. Lenhard, M. Malcho, Numerical simulation device for the transport of geothermal heat with forced circulation of media, in Mathematical and Computer Modelling, 2013, vol. 57, iss. 1-2, pp. 111-125.

[7] INCROPERA - DEWITT - BERGMAN - LAVINE. 2007. Fundamentals of Heat and Mass Transfer, 6 Edition.2007. ISBN-10:0470055545

[8] S. Bonnet, M. Alaphilippe, P. Stouffs: Study of a small Ericssonengine for household micro-cogeneration, Proceedings of the International Stirling Forum 2004, ECOS GmbH, Osnabrück, Germany (2004) 